\title{
Morphemic relationships in the lexicon: Are they distinct from semantic and formal relationships?
}

\author{
SHIRLEY E. NAPPS \\ Dartmouth College, Hanover, New Hampshire
}

\begin{abstract}
The influence of morphemic relationships on the repetition priming effect, which is presumed to provide an index of lexical organization, was examined in several experiments. An attempt was made in all experiments to minimize nonlexical contributions to these lexical effects by placing related items in a context of unrelated items. Priming among regularly and irregularly suffixed morphemic relatives, associates, and synonyms was examined. Morphemic relatives and associates yielded significant priming, although priming was largest for regularly suffixed morphemic relatives. Priming was not obtained for synonyms. In previous research (Napps \& Fowler, 1987), priming was not found among orthographically and phonologically related words. The results are interpreted to mean that morphemic priming is not the result of the convergence of semantic, orthographic, and phonological relationships, but rather that morphemic relationships are represented explicitly in the lexicon.
\end{abstract}

A morpheme is (roughly speaking; see Aronoff, 1976/ 1981) the smallest meaningful linguistic unit. It can be either a stem or an affix of a word, for example, both "boy" and "-s" in "boys" are morphemes. In the present study, two words are considered to be morphemically related if they share a stem. It is not necessary that words share meaning in order to be considered morphemic relatives (e.g., "terrify" and "terrific" are morphemic relatives that no longer have similar meanings), and it is not enough that words share a physical relationship (e.g., "card" and "car" overlap physically as much as do "cars" and "car," but only the latter two are morphemic relatives).

This research was designed to investigate the role of morphemic relationships in lexical organization. Are morphemic relationships represented explicitly in lexical organization or are morphemic relatives just phonologically, orthographically, and semantically related words?

In some models of lexical organization, morphemic relationships play a central role (e.g., Morton, 1969, 1979). Some other, almost complementary, models account for lexical organization based on formal (i.e., phonological and orthographic) relationships (e.g., McClelland \& Rumelhart, 1981; see also Dell \& Reich, 1981; Glushko, 1981; Stemberger 1982/1983). Both types of model account for a subset of the data currently available on lexical

This research was conducted in partial fulfillment of the requirements for the $\mathrm{PhD}$ degree at Dartmouth College. The author would like to thank her dissertation committee members, Jack Baird, Laurie Feldman, Carol Fowler, and George Wolford, for all the comments, criticism, help, and support they provided toward the completion of the dissertation. Thanks are also extended to Paula Schnurr and Mary Smith. Correspondence may be addressed to Shirley E. Napps, Department of Psychology, Dartmouth College, Hanover, NH 03755. access and organization. However, neither type of model accounts for all such evidence. Possibly, a model such as that of McClelland and Rumelhart should include a morphemic dimension and a model such as that of Morton should include orthographic and phonological dimensions.

There is a good deal of evidence that morphemic relatives are closely associated in the lexicon. One source of such evidence is provided by the repetition priming paradigm. This technique uses a lexical decision task in which letter strings are occasionally repeated. Forbach, Stanners, and Hochhaus (1974) found that lexical decisions to the second occurrences of words are facilitated relative to response times to first occurrences. These effects persist up to $48 \mathrm{~h}$ after the first occurrence (Scarborough, Cortese, \& Scarborough, 1977). The facilitation is presumably due to repeated access of the same lexical entry. Stanners, Neiser, Hernon, and Hall (1979) exploited this phenomenon to determine that morphemic relatives are closely associated lexically, since morphemically related words prime each other. Furthermore, results indicate that morphemic relatives are closely associated lexically whether or not they preserve each other's sound and spelling (Fowler, Napps, \& Feldman, 1985; Stanners et al., 1979).

Are morphemic relationships special, or are they just a convergence of semantic, orthographic, and phonological relationships? That is, are morphemic relationships stronger than, or different from, relationships that would be predicted on the basis of semantic, phonological, and orthographic similarity? As Gough, Alford, and HolleyWilcox (1981) point out, identity can be thought of as the extreme case of semantic relatedness. Indeed, if a word and its inflected forms are strongly associated in the lexicon, it could be argued that this is because they are nearly 
identical in meaning, differing only in number, tense, or aspect. A similar kind of argument could be put forth concerning the similarity between formal relationships and morphemic relationships. There is a great deal of evidence of priming among semantically related words (e.g., Dannenbring \& Briand, 1982; Meyer \& Schvaneveldt, 1971). However, comparisons of morphemic and semantic priming effects (Dannenbring \& Briand, 1982; Henderson, Wallis, \& Knight, 1984) have shown that morphemic effects are much larger and longer lived than semantic effects. In addition, there is evidence that word form is used for lexical access during production (e.g., Browman 1978/ 1979; Brown \& McNeill, 1966), but again, morphemic priming effects are far stronger than formal effects (Murrell \& Morton, 1974).

However, there may be reasons for the priming difference between morphemically related forms and semantically related forms (and, similarly, formally related forms) that are independent of lexical organization, but confounded with lexical effects, in the repetition priming paradigm. Strategic processes, postlexical effects, and episodic factors may all influence results found with repetition priming. DeGroot (1983) suggests that three processes underlie the lexical decision priming effect. Two of these are the automatic and strategic processes proposed in Posner and Snyder's (1975) theory of attention. The automatic process is presumably lexical. The strategic process, however, is nonlexical and may vary depending upon the task at hand (e.g., Becker, 1980; Shulman \& Davison, 1977; Tweedy \& Lapinski, 1981). For example, Tweedy and Lapinski found that the size of the semantic priming effect depends on the subject's perception of the usefulness of semantic relationships shared by words in a test list. When a high proportion of primes was followed by related targets, subjects learned to use this information to facilitate responses, but when a low proportion of primes was followed by related targets, subjects learned not to use the information provided by primes. Evidence for this is provided by much larger semantic priming effects in the former case than in the latter. These results indicate that, although organization in semantic memory determines semantic priming, the effects can be enhanced by strategic behavior.

The third process involved in the lexical decision task, according to deGroot (1983), is a "postaccess search for meaningfulness" (p. 90), in which semantic relationships among primes and targets are compared. When a target is unrelated to its prime, the postaccess search interferes with the subject's response and slows responding to the target (DeGroot, Thomassen, \& Hudson, 1982). This same process possibly causes facilitation in the case of a related prime and target, thus speeding the correct response to the target. Seidenberg, Waters, Sanders, and Langer (1984) found that such postlexical effects occurred in the lexical decision task but not the naming task. Although studies investigating this phenomenon typically involve the presentation of both prime and target on one trial (e.g., McNamara \& Altarriba, 1988), it is possible that subjects draw on relationships existing between primes and targets that are separated by one or more intervening items.

An issue related to those concerning strategic effects and postaccess effects involves the influence of episodic factors on lexical effects (cf. Tulving, 1972). Cross-modal priming, if it exists, indicates that lexical access is a significant contributor to within-modality effects. An episodic trace should have much less influence on responses that occur across modalities than on those that occur within the same modality. Cross-modal priming has been found for both repetition priming (e.g., Kirsner, Milech, \& Standen, 1983; Kirsner \& Smith, 1974) and semantic priming (e.g., Swinney, Onifer, Prather, \& Hirshkowitz, 1979). In studies designed to determine the extent of episodic contributions to priming effects found in the lexical decision task, there has been general agreement that the task does have a lexical component (e.g., Feustel, Shiffrin, \& Salasoo, 1983; Forster \& Davis, 1984; Jacoby \& Dallas, 1981).

In the present series of experiments, strategic processes, postlexical effects, and episodic factors were limited in several ways. The utility of strategic behavior was severely limited by the use of a context of unrelated items. Approximately $6 \%$ of the items a subject saw were words that were related in some fashion; that is, they were either exact repetitions or morphemic or semantic relatives of each other. To limit the occurrence of postlexical effects, the present experiments used lags between prime and target ranging from 0 to 10 , in addition to an unrelated context, in order to make it more difficult for subjects, at least at the longer lags, to be able to make use of relationships between stimuli. When unrelated items intervene between a prime and target, subjects should have a much more difficult time determining which words are related and how. This should discourage attempts to determine relationships among stimuli. Such behavior is limited further by having half of the critical (nonfiller) word primes paired with nonword targets that vary by one or two letters from a word target that would be expected for a given prime. ${ }^{1}$ The unrelated context should also decrease the subject's ability to form useful episodic traces.

The present series of experiments was designed to address the kinds of lexical relationships among words that might lead to priming, and to investigate morphemic and semantic relationships. Three degrees of similarity of morphemically related words were examined. Data on formal relationships are reported in Napps and Fowler (1987).

\section{EXPERIMENT 1}

Using visual presentation of stimuli, Fowler et al. (1985) found that suffixed forms of a word that preceded a base word by 48 trials in a lexical decision task led to significant facilitation effects in the base word regardless of whether or not the suffixed forms preserved the sound and/or spelling of the base word. However, the possibil- 
ity remained that some of this effect could be due to episodic or strategic factors, even though care was taken to limit such effects. In the present experiments, the possibility of contamination of lexical effects by episodic effects was minimized by reducing the proportion of related items in the task from $80 \%$ (in the Fowler et al., 1985, studies) to $6.26 \%$. (The term related items refers to primetarget word pairs that are related to each other in some way, being either repetitions or morphemic or semantic relatives.)

The purpose of the first experiment was to ascertain whether or not the priming effect for morphemic relatives would still be present with the reduced proportion of related items. This experiment was run with subsets of stimuli from previous experiments (Fowler et al., 1985, Experiments 2 and 3): one group included words that preserved the sound and spelling of base forms upon suffixation, and the other group included words that did not.

\section{Method}

Subjects. Eighty-two Dartmouth College undergraduates participated in this experiment for course credit. All subjects were native speakers of English and had normal or corrected vision. Usable data were collected from 72 subjects. Three subjects failed to reach a preselected accuracy criterion $(64 \%)$, so their data were excluded from analysis. ${ }^{2}$ The data of 3 other subjects were lost in power failures, and those of 4 were lost due to equipment failure.

Stimulus materials. The critical stimuli were 42 English words and 42 nonwords that served as targets. For each target word there were three primes, including the target (or base word) itself. The condition in which the target appeared unprimed will be called base-first (or Bl); the condition in which the target was primed by itself will be called base-base (BB). Thus, the data for the $\mathrm{B} 1$ condition are obtained from the first trial in a base-base prime-target sequence. Word stimuli were divided into two equal groups: regular and sound-and-spelling change. For the regular group, the additional two primes were: (1) an inflected form of the base word (inflection-base, or IB), and (2) a derived form of the base word (derivation-base, or DB); in neither case did the addition of the suffix change the sound or spelling of the base word. For instance, for the target "manage," the primes were "manage," "manages," and "manager." For these groups of stimuli, respective mean frequencies of occurrence in English (KuCera \& Francis, 1967) are 109,64 , and 42 . For the sound-and-spelling-change group, the additional primes were: (1) a suffixed form of the target that did not change the sound or spelling of the target upon suffixation (no-change-base, or $\mathrm{NCB}$ ) and (2) a suffixed form that changed the sound and spelling of the target upon suffixation (change-base, or CB). For example, primes of the target "assume" were "assume," "assumed," and "assumption." For these groups, mean frequencies of occurrence in English are 56, 31, and 24. In the sound-and-spelling-change group, approximately equal numbers of inflections and derivations were used as primes with the change and no-change conditions. Primes and targets for words are listed in Appendix A.

Nonword targets were primed with real words from each of the prime categories used with word targets. For instance, for the target "enlorne," primes were "enlarge," "enlarged," and "enlarger," and for the target "extel," primes were "expel," "expelling," and "expulsion." Nonwords were orthographically and phonemically regular and legal. ${ }^{3}$ They were created by substituting one or two letters of a word with other letters.

The $\mathbf{4 2}$ word items that served as targets for the relevant priming conditions will be referred to as related items, to distinguish them from filler items and from critical item trials in which the prime was a word and the target was a nonword. To decrease the chances that episodic or strategic factors would bias the results, filler items were used in all experiments to reduce the proportion of related items to which a subject would be exposed. In each experiment, the proportion of trials on which responses could be affected by the subject's recognizing a relationship between prime and target differed from the proportion of stimuli actually related to other stimuli. This was possible because primes and targets were presented on different trials. One-sixteenth $(6.26 \%)$ of the primetarget pairs were related to each other (there were 84 related items, 84 critical items involved in word-nonword pairs, and 1,174 filler items); however, since half of these stimuli were primes, and therefore would be responded to without knowledge of the relationship between prime and target, only $3.13 \%$ of a subject's responses would be made to targets preceded by a related prime. Filler items were matched as closely as possible to critical primes and targets both in length (in letters) and in frequency of occurrence in English. Filler items also included as many items as possible that were of the same syntactic classes as the critical stimuli. Fifty percent of the stimuli for the entire experiment were words and $50 \%$ were nonwords. Practice items were words and nonwords that were not necessarily of the same syntactic classes as the critical stimuli.

The subjects saw the same number of each type of prime, and they saw each base word only once as a target. A Latin square design was used to assign critical primes to groups of 3 subjects. For instance, for a given set of three critical targets, say "manage," "develop," and "enjoy," one subject would receive the prime-target pairs "manage-manage," "developed-develop," and "enjoymentenjoy," another would receive "manages-manage," "developmentdevelop," and "enjoy-enjoy," and the third would receive "managermanage," "develop-develop," and "enjoying-enjoy." Thus, each of the 3 subjects would receive a different prime for a given target and also equal numbers of each type of prime. A new random order of stimuli (both critical and filler items) was used for each group of 3 subjects.

Procedure. The subjects were tested individually. The experiment was presented on a time-sharing computer interfaced with a microprocessor ${ }^{4}$ The stimuli were presented in upper case on a cathode ray tube. On each trial, the following sequence of events occurred: (1) A fixation string of plus signs $(t+++++++)$ appeared in the center of the screen for $1,000 \mathrm{msec}$; (2) the terminal bell sounded $500 \mathrm{msec}$ before the fixation mark went off; (3) a letterstring appeared as soon as the fixation mark disappeared, and remained on until the subject responded; (4) once a response was made, the reaction time (in milliseconds) appeared for $1,000 \mathrm{msec}$ if the response was correct, or the word "ERROR" appeared for $1,250 \mathrm{msec}$ if the response was incorrect; (5) the screen went blank for $500 \mathrm{msec}$ before the fixation string for the next trial appeared.

For each subject, the $\mathbf{K}$ key of the computer terminal was pressed with the right index finger for a word stimulus and the D key was pressed with the left index finger for a nonword stimulus. The keys were labeled W and NW for "word" and "nonword," respectively.

For each subject, the test stimuli were divided in half, with the first half used in one session and the other half in a second session; the two sessions were separated by a break of at least $3 \mathrm{~h}$. Each subject completed 23 blocks of 61 trials each. The first block of the first session included only practice items, and the first block of the second session included only filler items. A subject responded to 168 critical items and 1,174 filler items. Of the 168 critical items, half involved stimuli with word targets and half involved stimuli with nonword targets. Half of these were regular items and half were sound-and-spelling-change items. All 42 word and nonword targets and 84 respective primes were presented to each subject. There were 545 word filler items and 629 nonword filler items.

Design. Independent variables were the within-subjects factor of prime type, which had four levels (B1, BB, IB, and DB for regular 
words and $\mathrm{B} 1, \mathrm{BB}, \mathrm{NCB}$, and $\mathrm{CB}$ for sound-and-spelling-change words), and the between-subjects factor of lag, which had three levels $(0,1$, and 10$)$. A lag is the number of items intervening between two members of a related prime-target pair. The two groups of words, regular and sound-and-spelling change, were analyzed separately. Dependent measures were response time (RT) to the target and accuracy.

\section{Results}

Errors and extreme RTs (less than $200 \mathrm{msec}$ or greater than $2,000 \mathrm{msec}$ ) were excluded from analysis. If a subject's response was incorrect on a prime (target), the RT for the corresponding target (prime) was not included in the analysis. Accuracy scores were treated somewhat differently; accuracy scores were based on correct responses independent of accuracy on the corresponding prime or target.

An accuracy criterion of $64 \%$ was set for the experiment; the cutoff was statistically established to be above chance at the .05 level, treating word and nonword responses as independent groups of responses. Mean RTs and percentages of errors are presented in Tables 1 and 2 .

Comparison of sound-and-spelling-change words with regular words revealed no significant effect of word type $\left[\min F^{\prime}(1,136)=0.87, p>.25 ; M S_{\mathrm{e}}=21,976.8\right.$ by subjects, $M S_{\mathrm{e}}=20,075.9$ by items] and no interaction of word type with any other factors. (See Clark, 1973, for a discussion of the minimum $F^{\prime}$ statistic.)

Regular words. For mean RTs, the main effect of prime type was significant $\left[\min F^{\prime}(3,157)=10.43, p<\right.$ $.001 ; M S_{\mathrm{e}}=2,004.38$ by subjects, $M S_{\mathrm{e}}=2,619.68$ by items]. Scheffe's tests showed that all three primed conditions $(\mathrm{BB}, \mathrm{IB}, \mathrm{DB})$ were significantly different from the B1 condition. (See DeGroot et al., 1982, for a discussion of appropriate baselines for priming tasks.) There were no differences among the $\mathrm{BB}, \mathrm{IB}$, and $\mathrm{DB}$ conditions. There was no effect of lag $\left[\min F^{\prime}(2,87)=2.25, p>\right.$ $.10 ; M S_{\mathrm{e}}=19,097.80$ by subjects, $M S_{\mathrm{e}}=2,305.46$ by items] and no prime type $\times$ lag interaction $\left[\min F^{\prime}(6,292)\right.$ $=1.25, p>.25]$.

There was a significant main effect of prime type on accuracy $\left[\min F^{\prime}(3,160)=3.34, p<.05 ; M S_{\mathrm{e}}=38.38\right.$ by subjects, $M S_{\mathrm{e}}=0.0043$ by items], but all individual comparisons of the $\mathrm{BB}, \mathrm{IB}$, and $\mathrm{DB}$ conditions with the B1 condition were marginal $\left[\min F^{\prime}(3,162)=2.19\right.$, $.05<p<.10$; means for $\mathrm{BB}, \mathrm{IB}$, and $\mathrm{DB}$ are equal]. No other accuracy analyses were significant.

Sound-and-spelling-change words. This group of words showed the same pattern of results as the regular group. There was a main effect of prime type on RT $\left[\min F^{\prime}(3,163)=8.25, p<.0001 ; M S_{\mathrm{e}}=2,817.00\right.$ by subjects, $M S_{\mathrm{e}}=3,564.95$ by items], with all primed conditions (BB, NCB, CB) being different from B1. There were no significant differences among the $B B, N C B$, and $\mathrm{CB}$ conditions. The effects of lag and the prime type $\times$ lag interaction were not significant (both $\min F^{\prime}$ s $<1$ ).

There was a main effect of prime type on accuracy $\left[\min F^{\prime}(3,191)=4.51, p<.01 ; M S_{\mathrm{e}}=57.20\right.$ by subjects, $M S_{\mathrm{e}}=0.0047$ by items], with BB, NCB, and CB all being responded to more accurately than $\mathrm{B} 1$, according to Scheffé's tests. There were no other accuracy effects.

\section{Discussion}

This experiment showed that, even with episodic and strategic effects minimized, making lexical decisions to suffixed forms of a base word facilitates subsequent responding to the base word in a task employing visual stimulus presentation.

These results are quite similar to the outcomes of Fowler et al.'s (1985) Experiments 2 and 3. In addition, as is typical for repetition priming, there was no lag effect. These results may be interpreted as evidence that the type of affixed forms employed here and their base forms are associated with each other in the internal lexicon.

Table 1

Response Times, ${ }^{*}$ Standard Deviations, and Percentage Errors for Regular Words in Experiment 1

\begin{tabular}{|c|c|c|c|c|c|c|c|c|c|c|c|c|}
\hline \multirow[b]{3}{*}{ Lag } & \multicolumn{12}{|c|}{ Prime Type } \\
\hline & \multicolumn{3}{|c|}{ Base-First } & \multicolumn{3}{|c|}{ Base-Base } & \multicolumn{3}{|c|}{ Inflection-Base } & \multicolumn{3}{|c|}{ Derivation-Base } \\
\hline & RT & $S D$ & $\mathrm{PE}$ & $\mathrm{RT}$ & $S D$ & $\mathrm{PE}$ & RT & $S D$ & $\mathrm{PE}$ & RT & $S D$ & $\mathrm{PE}$ \\
\hline 0 & 564 & 92 & 7.12 & 490 & 75 & 1.75 & 488 & 54 & 0.58 & 499 & 53 & 0.58 \\
\hline 1 & 576 & 74 & 6.54 & 532 & 107 & 1.75 & 525 & 66 & 3.54 & 513 & 69 & 2.33 \\
\hline 10 & 578 & 89 & 3.50 & 529 & 77 & 1.17 & 561 & 103 & 1.75 & 553 & 70 & 1.75 \\
\hline
\end{tabular}

*In milliseconds.

Table 2

Response Times,* Standard Deviations, and Percentage Errors for Sound-and-Spelling-Change Words in Experiment 1

\begin{tabular}{|c|c|c|c|c|c|c|c|c|c|c|c|c|}
\hline \multirow[b]{3}{*}{ Lag } & \multicolumn{12}{|c|}{ Prime Type } \\
\hline & \multicolumn{3}{|c|}{ Base-First } & \multicolumn{3}{|c|}{ Base-Base } & \multicolumn{3}{|c|}{ No Change-Base } & \multicolumn{3}{|c|}{ Change-Base } \\
\hline & $\mathrm{RT}$ & $S D$ & $\mathrm{PE}$ & $\mathrm{RT}$ & $S D$ & $\mathrm{PE}$ & RT & $S D$ & $\mathrm{PE}$ & RT & $S D$ & $\mathrm{PE}$ \\
\hline 0 & 585 & 94 & 8.33 & 515 & 117 & 0.58 & 505 & 66 & 3.54 & 532 & 108 & 2.38 \\
\hline 1 & 583 & 96 & 8.92 & 538 & 74 & 5.29 & 538 & 90 & 1.17 & 549 & 96 & 2.92 \\
\hline 10 & 595 & 95 & 5.27 & 540 & 75 & 2.38 & 546 & 88 & 0.58 & 569 & 84 & 1.75 \\
\hline
\end{tabular}

*In milliseconds. 


\section{EXPERIMENT 2}

It seems reasonable to assume that if forms that do preserve and forms that do not preserve the sound and spelling of their bases are associated with their bases lexically, then all irregular forms that do not preserve the sound and spelling of their base forms should also be associated with their base forms. Although this hypothesis is plausible, the available evidence suggests that it is not tenable. Kempley and Morton (1982) found no effect on responses to a word of prior presentation of one of its irregularly related morphemic forms. In their paradigm, which will be referred to as perceptual recognition, subjects study a list of words presented either visually or auditorily. The original study words, or words related to them along some dimension, are then presented tachistoscopically or heard in noise, and subjects are asked to identify the words. Murrell and Morton (1974) found that responses to a word or one of its ruleful morphemic relatives were facilitated in the test phase relative to responses to words that had not been presented in the study phase. This result, however, did not extend to morphemic relatives that did not preserve the sound and spelling of their base forms, for example, "held" and "holding," "men" and "man" (Kempley \& Morton, 1982).

In Experiment 2, I wanted to determine whether or not the finding of Experiment 1, that regular and irregular affixed forms prime their bases, would also hold in the present paradigm for forms that cannot be rulefully generated from their base forms, such as those used by Kempley and Morton (1982). With this end in mind, stimuli were devised according to the following constraints: (1) Affixed stimuli could not be rulefully generated from their bases, and (2) physical overlap was less for these stimuli than for those of the CB condition in Experiment 1 . As before, targets were base forms and primes-affixed forms.

The suppletive forms are a group of words for which these constraints can be realized. (A suppletion is a morphemically complex form that shares little physical resemblance with its base..$^{5}$ ) Instead of conforming to generation by rule, irregular forms are either entirely unsystematic or they conform to "schemata." Bybee (Bybee \& Moder, 1983; Bybee \& Slobin, 1982) has argued that a number of English verbs that are productive in the language but are learned by rote are really members of a morphemic class, and that these classes can be defined in terms of natural categories (cf. Rosch, 1975; Rosch, Mervis, Gray, Johnson, \& Boyes-Braem, 1976). Each past-tense form of one of these verbs fits into a particular "schema," inclusion being defined in terms of a prototypical class member and other members being more or less like the prototype. For instance, one schema includes "catch-caught" and "bring-brought," which are verbs whose past-tense forms rhyme with "ought." These schemata include many irregular past-tense forms, such as those we refer to as suppletive forms.
Bybee and Slobin (1982) suggest that, as in the foregoing example, the schemata employed are product-oriented (Zager, 1981, cited in Bybee \& Slobin); that is, class membership is determined by similarity of past-tense forms rather than of base forms. Accordingly, the class cannot be characterized by any rule that derives the pasttense forms from their disparate base forms. Like natural categories in general, the classes are not well defined; they include members that are more or less like the prototypical member.

The suppletive forms chosen for the present experiment and the CB forms of Experiment 1 differ in physical overlap, with the suppletive forms being, overall, less similar to their base forms than are the CB forms. ${ }^{6} \mathrm{~A} t$ test showed that the mean overlap of the sound-and-spelling change words of Experiment $1(0.58)$ was larger than that of the suppletive forms to be used in Experiment 2 [0.51; $t(49)=1.79, p<.05$ ]. The corresponding analyses for sound changes indicated a marginal difference between the two groups of stimuli. The sound-and-spelling-change words had a mean overlap of 0.53 , and the suppletive words had a mean overlap of $0.47[t(49)=1.30, .05<$ $p<.10$ ).

In summary, this experiment was designed to assess the priming effect of nonrulefully affixed words on their unaffixed base forms. Do the suppletive forms count, psychologically, as relatives of their base forms, or is there substantially less morphemic priming when there is less orthographic overlap between prime and target than occurs with the CB stimuli?

\section{Method}

Subjects. Seventy-two subjects participated in this experiment. Of these, 66 were from the same subject pool used previously and 6 were paid volunteers who were also Dartmouth undergraduates. None had participated in Experiment 1. Usable data were obtained from 64 subjects. The data of 1 subject were lost due to experimenter error. The data of 7 additional subjects were deleted, those of 6 because they failed to meet the accuracy criterion $(67 \%$; see Footnote 1) and those of 1 because the subject failed to return for the second session.

Stimulus materials. The critical stimuli were 30 English words (verbs) and 30 nonwords which served as targets. For each target word there were two primes: (1) the target itself (BB), and (2) the suppletive past-tense form of the target (suppletion-base, or SUP-B). For instance, for the target "catch," primes were "catch" and "caught." For these groups of stimuli, mean frequencies of $\alpha$ currence in English are 224 and 241. Primes and targets for words are listed in Appendix B. Nonwords were created and used in the same way as in Experiment 1. Together, the word and nonword suppletive forms essentially exhaust the population of irregular pasts in English. As in Kempley and Morton (1982), these were all inflections.

Filler items were used, as in Experiment 1, to reduce the percentage of related items to $6.26 \%$.

The subjects experienced the same number of each type of prime, and they saw each base word only once as a target. A Latin square design was used to assign critical primes to pairs of subjects. A new random order of stimuli was used for each pair of subjects.

Procedure. The procedure was virtually the same as that used in Experiment 1. Each subject completed 17 blocks of 64 trials each, 
in two sessions, as in Experiment 1. The first block of the first session involved all practice trials, and the first block of the second, all filler items. A subject responded to 120 critical items and 840 filler items. Of the critical items, half involved stimuli with word targets and half, stimuli with nonword targets. Each subject experienced all 30 word targets and nonword targets and 60 respective primes. There were 405 word filler items and 435 nonword filler items.

Design. Independent variables were the within-subjects factor of prime type, with three levels (B1, BB, and SUP-B), and the betweensubjects factor of lag, with four levels $(0,1,3$, and 10$)$. The lag of 3 was added to provide additional information should, for instance, priming occur at a lag of 1 but not at a lag of 10 . Dependent measures were RT to the target and accuracy.

\section{Results}

Errors and extreme RTs were excluded from analysis, as in Experiment 1. Errors and accuracy scores were treated as in Experiment 1. Mean RTs and percentages of errors are presented in Table 3.

There was a main effect of prime type on RTs $\left[\min F^{\prime}\right.$ $(2,141)=16.48, p<.001 ; M S_{e}=1,090.39$ by subjects, $M S_{e}=2,554.79$ by items], with both the BB and SUP-B conditions being different from the base-first condition according to Scheffé's tests. In addition, the BB RTs were significantly faster than the SUP-B times.

There was no effect of $\operatorname{lag}\left(\min F^{\prime}<1\right)$, and there was a nonsignificant prime type $\times$ lag interaction $\left[\min F^{\prime}(6,293)\right.$ $=1.08, p<.25]$. Although the interaction is not significant, the suppletive priming effect clearly is absent at the longer lags. This effect is $50 \mathrm{msec}$ at lags of 0 and 1 but only 2 msec at lags of 3 and 10 . It is possible that use of the minimum $F^{\prime}$ statistic is overly conservative in including an items analysis when approximately half of the population of irregular past-tense forms appeared as word stimuli in the experiment (see Wickens \& Keppel, 1983). In any case, there was no similar loss of priming at a lag of 10 in the $C B$ stimuli of Experiment 1.

Accuracy analyses showed that subjects were more accurate in the BB than in the $\mathrm{B} 1$ condition $\left[\min F^{\prime}(2,178)\right.$ $=2.77, .05<p<.10 ; M S_{\mathrm{e}}=18.50$ by subjects]. No other accuracy analyses were significant.

\section{Discussion}

In this experiment, suppletive past-tense forms did prime their bases, but not exactly as predicted. The priming was smaller than in Experiment 1 and was also much shorter lived, lasting only to a lag of 1 . These priming effects are much more reminiscent of semantic priming

Table 3

Response Times,* Standard Deviations, and Percentage Errors for Suppletive Words in Experiment 2

\begin{tabular}{|c|c|c|c|c|c|c|c|c|c|}
\hline \multirow[b]{3}{*}{ Lag } & \multicolumn{9}{|c|}{ Prime Type } \\
\hline & \multicolumn{3}{|c|}{ Base-First } & \multicolumn{3}{|c|}{ Base-Base } & \multicolumn{3}{|c|}{ Suppletion-Base } \\
\hline & RT & $\overline{S D}$ & $\mathrm{PE}$ & RT & $S D$ & $\mathrm{PE}$ & RT & $S D$ & $\mathrm{PE}$ \\
\hline 0 & 549 & 45 & 3.81 & 481 & 43 & 1.25 & 498 & 44 & 0.88 \\
\hline 1 & 570 & 129 & 2.19 & 510 & 76 & 0.00 & 521 & 103 & 1.31 \\
\hline 3 & 544 & 64 & 4.50 & 506 & 63 & 1.69 & 542 & 70 & 2.21 \\
\hline 10 & 544 & 72 & 3.88 & 506 & 84 & 2.56 & 542 & 97 & 3.81 \\
\hline
\end{tabular}

*In milliseconds (e.g., Dannenbring \& Briand, 1982) than of morphemic priming. Semantic priming is generally much shorter lived than morphemic priming and also tends to be smaller in magnitude (see, e.g., Henderson et al., 1984). The findings are also compatible with those of Kempley and Morton (1982), who found no priming between suppletive forms and their morphemic relatives with relatively long temporal lags between prime and target (10 to $40 \mathrm{~min}$ ).

\section{EXPERIMENT 3}

The priming found in Experiment 2 is similar in longevity to the semantic priming found by other researchers (Dannenbring \& Briand, 1982; Gough et al., 1981), who, however, used higher proportions of related prime-target pairs than I did in Experiment 2. Possibly, therefore, the priming in Experiment 2 reflects only the semantic relationship between prime and target. To evaluate this possibility, I next examined semantic priming by using the paradigm of Experiments 1 and 2. To ensure comparability of semantic priming effects with the effects obtained in Experiment 2, I examined priming by associates and synonyms, using a lower proportion of related items than is generally used in similar research.

\section{Method}

Subjects. Sixty-one subjects, from the same subject pool used in Experiments 1 and 2, served in this experiment. None had served in either of the other experiments. Usable data were obtained from 60 subjects. The data of 1 subject were deleted because the subject failed to make the accuracy cutoff $(63 \%$; see Footnote 2$)$.

Stimulus materials. The critical stimuli were 63 English words and 63 nonwords that served as targets. For each target word there were two primes, including the target itself. The other prime was either a word for which the target was an associate (associatebase, or AB) or a synonym of the target (synonym-base, or SYN-B). For instance, for the word "pain," the primes were "pain" and "ache." For associates, mean frequencies of occurrence in English for these stimulus groups are 126 and 126 . For synonyms, the respective frequencies are 90 and 81 .

The synonymous and associative primes used in this study were obtained from two pilot studies. In one, subjects rated pairs of words on their closeness in meaning. Half of the words came from association norms (Keppel \& Strand, 1970; Palermo \& Jenkins, 1964) and half from synonym ratings (Whitten, Suter, \& Frank, 1979). The 32 associate pairs and 31 synonym pairs that received the highest ratings were chosen as stimuli for Experiment 3. Mean semantic ratings on a 7-point scale (where 7 designates a very strong relationship and 1 , a very weak relationship) were 4.95 for associate pairs and 6.24 for synonym pairs. No pair chosen as a stimulus pair for Experiment 3 received a rating lower than 4 . These stimuli were then tested in a second pilot study to ascertain whether or not they would lead to priming under standard semantic priming conditions (i.e., lag of 0 ); $98 \mathrm{msec}$ of priming was obtained for synonymous and associative pairs using the present "base first" condition as a baseline measure. Real-word associate and base forms are listed in Appendix C; real-word synonym and base forms are listed in Appendix D.

Nonwords were created and used in the same way as in previous experiments.

Filler items were employed as before to reduce the percentage of related items to $6.26 \%$.

The subjects saw the same number of each prime type and they saw each base word only once as a target. A Latin square design 
assigned critical primes to pairs of subjects, ${ }^{7}$ and the stimuli were randomly ordered, as in previous experiments.

Procedure. The procedure was virtually the same as that used in Experiment 1. Each subject completed 23 blocks of 61 trials each, in two sessions, as in Experiment 1. The first block of the first session was comprised entirely of practice trials, and the first block of the second session, all filler items. A subject responded to 252 critical items and 1,090 filler items. Of the critical items, half were stimuli with word targets and half were stimuli with nonword targets. Each subject received all 63 word targets and nonword targets and 126 of their respective primes. There were 482 word filler items and 608 nonword filler items.

Design. Independent variables were the within-subjects factor of prime type, which had three levels (BI, BB, and AB or SYN-B), and the between-subjects factor of lag, which had four levels $(0,1,3$, and 10). Dependent measures were RT to the target and accuracy.

\section{Results}

Errors and extreme RTs were excluded as previously. Errors and accuracy scores were treated as before.

Comparison of associates and synonyms revealed a marginal main effect of word type $\left[\min F^{\prime}(1,172)=3.03\right.$, $.05<p<.10 ; M S_{e}=11,028.8$ by subjects, $M S_{c}=$ $18,120.9$ by items], with subjects responding faster overall to associative primes and targets than to synonymous primes and targets, with means of 516 and $540 \mathrm{msec}$, respectively. There were no significant interactions of word type with any other factors. ${ }^{8}$ To allay any fears that the two groups of stimuli function differently, however, the data from associates and synonyms were analyzed separately. Mean RTs and percentages of correct responses, collapsed over lags, are presented in Tables 4 and 5.

Associates. The main effect of prime type was significant for mean RTs $\left[\min F^{\prime}(2,136)=12.35, p<.001\right.$; $M S_{\mathrm{e}}=1,070.25$ by subjects, $M S_{\mathrm{e}}=3,626.09$ by items]. Scheffé's tests showed that the BB condition was different from the B1 condition $\left[\min F^{\prime}(2,137)=12.27, p<\right.$ $.001]$. Associative priming was also significant $\left[\min F^{\prime}(2,126)=3.31, p<.05\right]$. In addition, the $\mathrm{BB}$ and $\mathrm{AB}$ conditions were marginally different $\left[\min F^{\prime}(2,150)\right.$ $=2.79, .05<p<.10]$. There was no main effect of lag and no prime type $\times$ lag interaction.

None of the variables produced any significant effects on accuracy.

Synonyms. The main effect of prime type was significant for mean RTs $\left[\min F^{\prime}(2,141)=8.84, p<.001 ; M S_{\mathrm{e}}\right.$ $=1,642.67$ by subjects, $M S_{\mathrm{e}}=5,372.2$ by items]. Scheffe's tests showed that the BB condition was different

Table 4

Response Times,* Standard Deviations, and Percentage Errors for Associates in Experiment 3

\begin{tabular}{|c|c|c|c|c|c|c|c|c|c|}
\hline \multirow[b]{3}{*}{ Lag } & \multicolumn{9}{|c|}{ Prime Type } \\
\hline & \multicolumn{3}{|c|}{ Base-First } & \multicolumn{3}{|c|}{ Base-Base } & \multicolumn{3}{|c|}{ Associate-Base } \\
\hline & RT & $S D$ & PE & RT & $S D$ & $\mathrm{PE}$ & RT & $S D$ & PE \\
\hline 0 & 545 & 60 & 3.80 & 485 & 52 & 0.00 & 496 & 46 & 1.20 \\
\hline 1 & 537 & 73 & 4.87 & 487 & 54 & 3.73 & 503 & 38 & 2.53 \\
\hline 3 & 528 & 61 & 4.87 & 503 & 53 & 0.67 & 532 & 87 & 1.80 \\
\hline 10 & 552 & 66 & 4.27 & 497 & 64 & 3.13 & 524 & 62 & 4.27 \\
\hline
\end{tabular}

*In milliseconds.
Table 5

Response Times, , Standard Deviations, and Percentage Errors for Synonyms in Experiment 3

\begin{tabular}{|c|c|c|c|c|c|c|c|c|c|}
\hline \multirow[b]{3}{*}{ Lag } & \multicolumn{9}{|c|}{ Prime Type } \\
\hline & \multicolumn{3}{|c|}{ Base-First } & \multicolumn{3}{|c|}{ Base-Base } & \multicolumn{3}{|c|}{ Synonym-Base } \\
\hline & RT & $S D$ & PE & RT & $S D$ & PE & RT & $S D$ & PE \\
\hline 0 & 550 & 51 & 8.27 & 523 & 74 & 1.93 & 544 & 82 & 6.13 \\
\hline 1 & 562 & 72 & 8.33 & 514 & 88 & 2.67 & 539 & 39 & 7.60 \\
\hline 3 & 581 & 85 & 6.27 & 507 & 57 & 2.47 & 540 & 78 & 7.07 \\
\hline 10 & 547 & 79 & 7.07 & 511 & 68 & 0.60 & 562 & 93 & 10.87 \\
\hline
\end{tabular}

*In milliseconds.

from the $\mathrm{B} 1$ condition $\left[\min F^{\prime}(2,139)=8.07, p<.001\right]$. Synonym priming, however, was not significant [for SYN-B compared with B1, $\min F^{\prime}(2,100)=0.44$; for SYN-B compared with $\mathrm{BB}, \min F^{\prime}(2,153)=4.33, p<$ $.05]$. There was no main effect of lag and no prime type $\times$ lag interaction.

There was a significant main effect of prime type on accuracy $\left[\min F^{\prime}(2,107)=4.06, p<.05 ; M S_{\mathrm{e}}=0.0046\right.$ by subjects, $M S_{e}=0.0241$ by items], which was due to the subjects' responding more accurately in the BB condition than in either the B1 or SYN-B condition.

\section{Discussion}

For synonyms, no priming was found. Associates did lead to significant priming, as compared with the B1 condition. In addition, associative priming was marginally smaller than $\mathrm{BB}$ priming.

How do these results compare with the suppletive priming effects found in Experiment 2? For suppletions, as for associates, priming is significant, but it is much less than that of the BB condition. Synonyms differ from suppletions and associates; they do not show statistically significant priming.

Comparisons of the suppletive, associative, and synonymous stimuli were made to determine whether strength of semantic relationships between primes and targets could account for suppletive priming. A group of subjects was asked to rate semantic relationships of prime-target pairs from these groups of stimuli. ${ }^{9}$ On a 7 -point scale (7 representing the strongest semantic relationships), the respective mean ratings were $5.49,4.95$, and 6.24 for suppletions, associates, and synonyms. It is the group of stimuli with the strongest rated meaning relationships that fails to cause priming. Thus, it seems unlikely that meaning alone can account for suppletive priming.

\section{GENERAL DISCUSSSION}

Four major results emerge from this series of experiments: (1) Morphemic relatives prime each other in most cases regardless of whether or not they maintain each other's sound and spelling; (2) suppletive verb forms lead to small amounts of priming in their bases, but these effects are very short-lived; (3) under the conditions of the present experiments, associates prime each other but synonyms do not, and (4) (from Napps \& Fowler, 1987) formal relatives do not prime each other. 
The intent of this research was to address the cause of morphemic priming. Priming was found for all morphemic relatives and for associates under conditions that minimize strategic and episodic sources of priming. The change and no-change stimuli of Experiment 1 lead to priming that is statistically the same as repetition priming. The suppletions and associates lead to statistically smaller effects than do exact repetitions. Can these effects be accounted for in some way by formal and semantic relationships between primes and targets?

Formal relationships failed to lead to priming in Napps and Fowler's (1987) Experiment 2, under conditions identical to those of the present studies. This lack of formal priming is not surprising, given previous research. The studies that find some type of formal priming are relatively few and far between, and seem to indicate that formal priming occurs for only certain types of stimuli (e.g., Forster, Davis, Schoknecht, \& Carter, 1987; Monsell, 1985). Thus, as data accumulate, it appears that there may be differences between production and comprehension processes concerning formal relationships among words. Formal relationships cause some effects in visual and auditory language comprehension (e.g, Glushko, 1979), although they are not always found (e.g., Murrell \& Morton, 1974). However, speech errors often show the effects of formal relationships on language production.

Direct comparison of semantic ${ }^{9}$ and formal ${ }^{10}$ relationships among various groups of stimuli strengthens the conclusion suggested by the outcomes of these experiments. Priming among morphemic relatives cannot be explained as the combined effects of semantic and formal priming (see also Henderson et al., 1984). There is no difference in semantic relatedness favoring morphemic relatives over synonyms, yet morphemic priming is obtained and synonym priming is not. Likewise, there is no difference in formal overlap that favors morphemic relatives over formal relatives, yet morphemic priming is obtained and formal priming is not. Thus these results imply that morphemic priming is a separate dimension along which two words can be related.

Such an interpretation does not, however, account for the similarities between suppletive and associative priming, or why it is that associates, but not synonyms, lead to priming. A simple semantic relationship explanation is improbable, since, although they have much stronger relationships than do suppletions and associates, synonyms cause no priming. The concept of schemata may be invoked here as a common factor in prime-target relationships among suppletions and associates. In general, associates may be thought of as being linked to each other through schemata; for example, "doctor" and "nurse" are not synonyms, but they share a strong relationship because of our schema of the involvement of both doctors and nurses in the treatment of patients. Suppletions are also possibly associated through schemata, as described in the introduction to Experiment 2, albeit very different types of schemata from the doctor-nurse variety. Whether such schemata actually can account for suppletive as well as associative priming, or whether sup- pletive priming is strictly morphemic in origin, cannot be determined from the data presented here.

Other possible explanations of priming found in the present experiments include frequency attenuation (see Forster \& Davis, 1984), practice effects, and episodic and strategic factors. Frequency attenuation refers to the case in which repetition effects are smaller for high-frequency words than for low-frequency words. To test for the possibility that the present effects merely represent frequency attenuation, priming effects and frequencies of occurrence in English were correlated for the 177 primed stimuli (excluding the BB condition) included in the three studies. The priming effect used in these correlations was the difference between RTs in the B1 and primed conditions. For frequency of prime, the correlation between frequency and priming was -.091; for target frequency, this correlation was -.079. Thus, it is apparent that there is little relationship between either prime or target frequency and size of priming effect.

Practice effects could perhaps enhance the priming effects found in these experiments, since the baseline (or B1) condition always occurs earlier in the stimulus list than do any of the primed conditions. The stimuli employed in Experiment 3 were tested for practice effects, and none were found. ${ }^{11}$ It therefore seems unlikely that the present results are compromised in some way by practice effects.

In recent years, considerable attention has been focused on possible episodic and strategic contributions to results obtained using the lexical decision task. Jacoby (1983a, 1983b), Forster and Davis (1984), Oliphant (1983), and Salasoo, Shiffrin, and Feustel (1985) have all provided evidence that episodic memory can play a role in lexical decisions. Seidenberg et al. (1984) have questioned the contribution that various postlexical processes make to lexical decision results. Balota and Chumbley (1985) point out similar problems with the naming task. Rugg (1987) has developed a method of investigating truly lexical effects without contamination by other factors. In addition, McClelland and Rumelhart (1985) have created a model that very elegantly accounts for both components of repetition effects.

This is all good and well, and the development of a new task would certainly quell a good deal of the controversy concerning the use of the repetition-priming lexical-decision task to study lexical organization. There are, however, reasons to continue to use lexical decision. Obviously, the decision does require lexical access, and findings of differential amounts of priming for different types of prime-target relationships may therefore be informative about relationships among words in the lexicon. Repetition effects for exact repetitions last up to $48 \mathrm{~h}$, whereas semantic priming lasts only to a lag of 1 . Morphemic priming effects do occur-a fact not explained by an episodic account-and they are much larger (in milliseconds) than semantic effects. Unrelated words show no priming at all (or even interference). One would expect that if priming in the lexical decision task were solely episodic, the opportunity was provided in the present study and in 
Napps and Fowler for it to obtain with formally and semantically related pairs. Note especially that even at a lag of 0 priming did not obtain for formal and synonymous word pairs, in which case relationships among related items should have been quite transparent. Obviously, more evidence is needed to determine the specific contributions made to this task by episodic and lexical components.

The data discussed in this paper can be summarized quite simply. Most morphemic relatives are associated in the lexicon; irregular past tense forms are less closely related than other forms. Associates are related in the same fashion as irregular morphemic relatives. Semantic relationships play a different role in lexical access than do morphemic and associative relationships. Rather than contributing to lexical organization, per se, the observed effects are created by relationships existing in semantic memory. Formal overlap does not contribute to lexical organization, per se. Any formal effects take place in an access system like that described in McClelland and Rumelhart's (1981) model of context effects in letter perception. Finally, episodic and strategic factors can contribute to results obtained using the lexical-decision task.

\section{REFERENCES}

ARONOFF, M. (1981). Word formation in generative grammar. Cambridge, MA: MIT Press. (Original work published 1976)

Balota, D. A., Chumbley, J. I. (1985). The locus of word-frequency effects in the pronunciation task: Lexical access and/or production? Journal of Memory \& Language, 24, 89-106.

BeCKer, C. A. (1980). Semantic context effects in visual word recognition: An analysis of semantic strategies. Memory \& Cognition, 8 , 493-512.

Browman, C. P. (1979). Tip of the tongue and slip of the ear: Implications for language processing (Doctoral dissertation, University of California, Los Angeles, 1978). Dissertation Abstracts International, 39, 4213A.

Brown, R., \& MCNEILL, D. (1966). The "tip of the tongue" phenomenon. Journal of Verbal Learning \& Verbal Behavior, 5, 325-337.

Bybee, J. L., Moder, C. L. (1983). Morphemic classes as natural categories. Language, 59, 251-270.

Bybee, J. L., \& Slobin, D. I. (1982). Rules and schemas in the development and use of the English past tense. Language, 58, 265-289.

CLARK, H. H. (1973). The language-as-fixed-effect fallacy: A critique of language statistics in psychological research. Journal of Verbal Learning \& Verbal Behavior, 12, 335-359.

Dannenbring, G. L., \& Briand, K. (1982). Semantic priming and the word repetition effect in a lexical decision task. Canadian Journal of Psychology, 36, 435-444.

DeGroot, A. M. B. (1983). Primed lexical decision: Combined effects of the proportion of related prime-target pairs and the stimulus-onset asynchrony of prime and target. Manuscript submitted for publication.

DeGroot, A. M. B., Thomassen, A. J. W. M., \&udson, P. T. W. (1982). Associative facilitation of word recognition as measured from a neutral prime. Memory \& Cognition, 10, 358-370.

Dell, G. S., \& ReICH, P. A. (1981). Stages in sentence production: An analysis of speech error data. Journal of Verbal Learning \& Verbal Behavior, 20, 611-629.

Feustel, T. C., Shiffrin, R. M., \& Salasoo, A. (1983). Episodic and lexical contributions to the repetition effect in word identification. Jourmal of Experimental Psychology: General, 112, 309-346.

Forbach, G. B., Stanners, R. F., Hochhaus, L. (1974). Repetition and practice effects in a lexical decision task. Memory \& Cognition, 2, 337-339.

Forster, K. I., \& DAvIs, C. (1984). Repetition priming and frequency attenuation in lexical access. Journal of Experimental Psychology: Learning, Memory, \& Cognition, 10, 680-698.
Forster, K. I., Davis, C., Schoknecht, C., \& Carter, R. (1987). Masked priming with graphemically related forms: Repetition or partial activation? Quarterly Journal of Experimental Psychology, 39A, 211-251

Fowler, C. A., Napps, S. E. \& Feldman, L. (1985). Lexical entries are shared by regular and irregular, morphemically related words. Memory \& Cognition, 13, 241-255.

GLushko, R. J. (1979). The organization and activation of orthographic knowledge in reading aloud. Journal of Experimental Psychology: Human Perception \& Performance, 5, 674-691.

GLushko, R. J. (1981). Principles for pronouncing print: The psychology of phonography. In A. M. Lesgold \& C. A. Perfetti (Eds.), Interactive processes in reading (pp. 61-84). Hillsdale, NJ: Erlbaum.

Gough, P. B., Alford, J. A. \& Holley-Wilcox, P. (1981). Words and contexts. In O. J. L. Tzeng \& H. Singer (Eds.), Perception of print: Reading research in experimental psychology (pp. 85-102). Hillsdale, NJ: Erlbaum.

Henderson, L., Wallis, J., \& KNIGHT, D. (1984). Morphemic structure and lexical access. In H. Bouma \& D. G. Bouwhuis (Eds.), At tention and performance, $X$ : Control of language processes (pp. 211 225). Hillsdale, NJ: Erlbaum.

JACOBY, L. L. (1983a). Perceptual enhancement: Persistent effects of an experience. Journal of Experimental Psychology: Learning, Memory, \& Cognition, 9, 21-38.

JACOBY, L. L. (1983b). Remembering the data: Analyzing interactive processes in reading. Journal of Verbal Learning \& Verbal Behavior, $22,485-508$.

JACOBY, L. L., \& DALLAS, M. (1981), On the relationship between autobiographical memory and perceptual learning. Joumal of Experimental Psychology: General, 110, 306-340

Kempley, S. T., \& MorTon, J. (1982). The effects of priming with regularly and irregularly related words in auditory word recognition. British Journal of Psychology, 73, 441-454.

KePpel, G., \& StRand, B. Z. (1970). Free-association responses to the primary responses and other responses selected from the PalermoJenkins norms. In L. Postman \& G. Keppel (Eds.), Norms of word association (pp. 177-239). New York: Academic Press.

Kirsner, K., Milech, D., Standen, P. (1983). Common and modality-specific processes in the lexicon. Memory \& Cognition, 11, $621-630$

KIRSNER, K. \& SMITH, M. C. (1974). Modality effects in word identification. Memory \& Cognition, 2, 637-640.

KUČERA, H., FRANCIS, W. (1967). Computational analysis of presentday American English. Providence, RI: Brown University Press.

MCClelland, J. L., \& Rumelhart, D. E. (1981). An interactive activation model of context effects in letter perception: Part 1. An account of basic findings. Psychological Review, 88, 375-407.

McClelland, J. L., Rumelhart, D. E. (1985). Distributed memory and the representation of general and specific information. Journal of Experimental Psychology: General, 114, 159-188.

McNamara, T. P., A Altarriba, J. (1988). Depth of spreading activation revisited: Semantic mediated priming occurs in lexical decisions. Journal of Memory \& Language, 27, 545-559.

Meyer, D. E., \&Chvaneveldt, R. W. (1971). Facilitation in recognizing pairs or words: Evidence of a dependence between retrieval operations. Journal of Experimental Psychology, 90, 227-234.

Monsell, S. (1985). Repetition and the lexicon. In A. W. Ellis (Ed.), Progress in the psychology of language (Vol. 2, pp. 147-195). London: Erlbaum.

MoRTon, J. (1969). Interaction of information in word recognition. Psychological Review, 76, 165-178.

MorTon, J. (1979). Facilitation in word recognition: Experiments causing change in the logogen model. In P. A. Kolers, M. Wrolstad, \& H. Bouma (Eds.), Processing of visible language, $I$ (pp. 259-268). New York: Plenum.

Murrell, G. A., \& Morton, J. (1974). Word recognition and morphemic structure. Journal of Experimental Psychology, 102, 963-968.

NAPes, S. E., \& Fowler, C. A. (1987). Formal relationships among words and the organization of the mental lexicon. Journal of Psycholinguistic Research, 16, 257-272.

Oluphant, G. W. (1983). Repetition and recency effects in word recognition. Australian Journal of Psychology, 35, 393-403, 
Palermo, D. S., \& Jenkins, J. J. (1964). Word association norms: Grade school through college. Minneapolis: University of Minnesota Press.

Posner, M. I., \& SNyder, C. R. R. (1975). Attention and cognitive control. In R. L. Solso (Ed.), Information processing and cognition. The Loyola symposium. Hillsdale, NJ: Erlbaum.

Rosch, E. (1975). Cognitive representations of semantic categories. Journal of Experimental Psychology: General, 104, 192-233.

Rosch, E., Mervis, C. B., Gray, W. D., Johnson, D. M., \& BoyesBraEM, P. (1976). Basic objects in natural categories. Cognitive Psychology, 8, 382-439.

RugG, M. D. (1987). Dissociation of semantic priming, word and nonword repetition effects by event-related potentials. Quarterly Journal of Experimental Psychology, 39A, 123-148.

Salasoo, A., Shiffrin, R. M., \& Feustel, T. C. (1985). Building permanent memory codes: Codification and repetition effects in word identification. Journal of Experimental Psychology: General, 114, 50-77.

Scarborough, D. L., Cortese, C., \& Scarborough, H. S. (1977). Frequency and repetition effects in lexical memory. Journal of Experimental Psychology: Human Perception \& Performance, 3, 1-17.

Seidengerg, M. S., Waters, G. S., Sanders, M., \& Langer P. (1984). Pre- and postlexical loci of contextual effects on word recognition. Memory \& Cognition, 12, 315-328.

Shulman, H. G., \& Davison, T. C. B. (1977). Control properties of semantic coding in a lexical decision task. Journal of Verbal Learning \& Verbal Behavior, 16, 91-98.

Stanners, R. F., Neiser, J. J., Hernon, W. P., \& Hall, R. (1979). Memory representation for morphemically related words. Journal of Verbal Learning \& Verbal Behavior, 18, 399-412.

Stemberger, J. P. (1983). The lexicon in a model of language production (Doctoral dissertation, University of California, San Diego, 1982). Dissertation Abstracts International, 43, 791A.

Swinney, D. A., Onifer, W., Prather, P., \& Hirshkowitz, M. (1979). Semantic facilitation across sensory modalities in the processing of individual words and sentences. Memory \& Cognition, 7, 159-165.

Tulving, E. (1972). Episodic and semantic memory. In E. Tulving \& W. Donaldson (Eds.), Organization of memory (pp. 381-403). New York: Academic Press.

TWEEDY, J. R, , \& LAPINSKI, R. H. (1981). Facilitating word recognition: Evidence for strategic and automatic factors. Quarterly Journal of Experimental Psychology, 33A, 51-59.

Whitten, W. B., II, Suter, W. N., \& Frank, M. L. (1979). Bidirectional synonym ratings of 464 noun pairs. Journal of Verbal Learning \& Verbal Behavior, 18, 109-127.

WiCKENS, T. D., \& KEPPEL, G. (1983). On the choice of design and of test statistic in the analysis of experiments with sampled materials. Journal of Verbal Learning \& Verbal Behavior, 22, 296-309.

\section{NOTES}

1. These experiments were initially designed as part of a larger study, a subset of which is described in Napps and Fowler (1987). In Experiment 1 of Napps and Fowler, primes and targets were separated by SOAs, rather than by lags, as presented here. In the SOA studies, critical nonword targets were preceded by word primes to avoid providing subjects with clues as to which trials were word and which were nonword ones. Since we wished to compare results obtained by using SOAs with those obtained by using lags, nonwords were treated in the same way as in Napps and Fowler's Experiment 2, which used lags rather than SOAs. The present studies involved the same type of critical nonword trials, partly as a holdover from the Napps and Fowler studies. Thus, nonword results are not clearly meaningful and are not reported here.

2. It was necessary to establish accuracy criteria statistically in this and subsequent experiments, since the number of trials a subject had to complete was extremely large; this made the task tiresome for subjects and difficult for them to maintain accuracy levels throughout an experimental session.

3. "Regular" refers to the mapping between letters and sounds, and "legal" refers to the sequencing of letters per se. The two are not identical because a letter sequence can be regular without being a legal En- glish letter sequence, as in, for example, "duk." It is possible to map the sequence "duk" onto a regular legal sequence (i.e., "duke"), but a word cannot end in the sequence "uk."

4. Microprocessor developed by Mike Layton, AGS Corporation, Box 64, Hanover, NH 03755 .

5. As they are defined in a strict sense, there are few true suppletions in the English language. "Went" and the forms of "be" are true suppletions because they are morphemically complex forms that share no physical overlap with their unaffixed counterparts.

6. Physical overlap was determined by pairing matching letters (phonemes) of the prime and target and drawing lines between matching letters in such a way that there were no crossovers of matches (i.e., so that matching letters [phonemes] are not counted if they are in different orders in the two words, so lines connecting the letter- or phoneme-pairs will intersect). Then other nonmatching letters (phonemes) were paired with the letters (phonemes) that were left. If there was no letter (phoneme) with which to pair a given letter (phoneme), a null character was inserted for pairing. Overlap was scored as the proportion of the number of matching letters (phonemes) to the number of possible matches (i.e., number of letters [phonemes] in the longer word of the pair). For instance, for the pair "caught-catch," orthographic overlap was determined as follows:

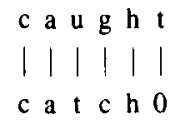

By this method, the degree of orthographic overlap for this pair is .5 , as the $c, a$, and $h$ match, but the other three letters do not. For any pair, the score given could be no smaller than 0 and no larger than 1 . Whenever a crossover for a match was possible, the pair was scored in both ways and the larger score was used.

7. When this experiment was designed, the intention was to collapse associative and synonymous stimuli in the same analysis. The stimuli were not divided into two groups for the purpose of assignment to subjects, so the subjects did not necessarily receive equal numbers of each prime type within each stimulus group.

8. To equate the associate and synonym word groups for purposes of these analyses, one target and its respective primes (i.e., "wool”) were chosen and omitted randomly.

9. Mean semantic ratings were obtained and compared for the groups of stimuli used in Experiments 1-3. On a 7-point scale, mean semantic ratings were: change stimuli, 5.31; no-change stimuli, 5.47; suppletions, 5.49; associates, 4.95; and synonyms, 6.24 . Twenty-five subjects provided semantic ratings. The data of 2 subjects were discarded because of failure to follow instructions.

Stimuli were prime-target pairs which came from the groups of word stimuli used in Experiments 1-3. The following groups of stimuli were used: the IB (inflection), DB (derivation), NCB (no-change), and CB (change) pairs from Experiment 1 ( $N=21$ for each type of pair), the SUP-B (suppletion) pairs from Experiment $2(N=30)$, the AB (associate) and SYN-B (synonym) pairs from Experiment $3(N=63)$, and the UB (unrelated, $N=63$ ) pairs from Experiment 2 of Napps and Fowler (1987). A new random order of pairs was used for each subject.

Subjects were tested in groups. Each subject received an instruction sheet and a test booklet containing all 240 pairs of words. Below each word pair was a 7-point rating scale on which the subject was asked to rate the strength of the meaning relationship of the pair of words. The rating 7 was designated to mean a very strong relationship, and the rating 1 , to mean a very weak relationship, with other relationship strengths falling somewhere in between. So that they would have some idea of the range of relationships included in the list, the subjects were instructed to read through the entire booklet quickly before beginning the rating task. Once the subjects began the task, they were asked to go through it as quickly as possible while still making responsible decisions. The subjects were allowed as much time as necessary to complete the task, which took the majority of them 25 to $35 \mathrm{~min}$.

10. Comparisons of orthographic and phonological overlap were made among several groups of stimuli. To make the comparison of formal relatedness, the measure of relatedness described in Footnote 6 was employed. Specifically, the overlap of the formally related pairs of Napps and Fowler's (1987) Experiment 2 was compared with overlap for stimuli 
used in the experiments presented here. A formally related pair is a pair in which the prime is a word graphemically identical to the target with a "pseudosuffix" (i.e., letters extending beyond the target itself) which makes the word semantically unrelated to the target. For example, for the target "rib," the prime was "ribbon." Mean orthographic overlap scores for the respective groups of stimuli are as follows: formally related stimuli, .66; change and no-change stimuli, .68; suppletions, .51; associates, .16; and synonyms, .13. Mean phonological overlap scores are: formally related stimuli, .65 ; change and no-change stimuli, .65; suppletions, . 47 ; associates, .14; and synonyms, .16. The formally related stimuli are generally more similar to each other both orthographically and phonologically than are other stimuli.

11. The critical word items used in Experiment 3 were tested for practice effects. For the first 11 blocks of trials (those involved in the first experimental session for each subject), there was no significant main effect of blocks in a subjects analysis $\left(\min F^{\prime}=1.54, p>.10, M S_{\mathrm{e}}\right.$ $=7,602 \cdot 27$ ). Because of the many random orders of stimuli involved in the experiment, an items analysis was not performed; with a nonsignificant subjects analysis, however, it would be nearly impossible for the minimum $F^{\prime}$ to be significant.

\section{APPENDIX A}

Base Items and Primes of Morphemically Related Stimuli from Experiment 1

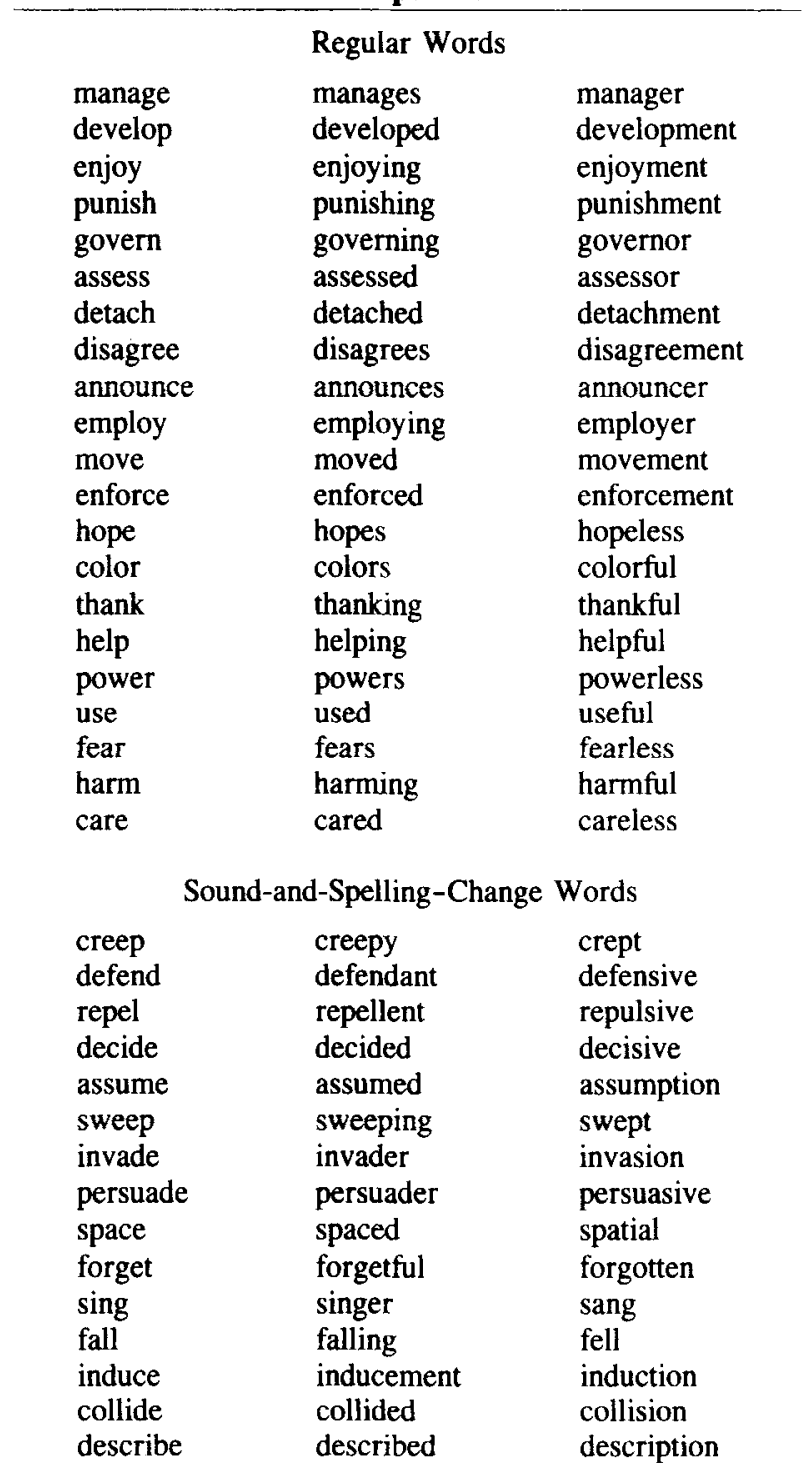

\begin{tabular}{lll} 
concede & conceded & concession \\
deep & deeply & depth \\
picture & picturesque & pictorial \\
propel & propeller & propulsion \\
wise & wisely & wisdom \\
clear & clearly & clarify \\
\hline
\end{tabular}

\section{APPENDIX B}

Base Items and Primes of Suppletive Stimuli from Experiment 2

\begin{tabular}{ll}
\hline bear bore & bring brought \\
buy bought & do did \\
eat ate & find found \\
keep kept & lie lay \\
light lit & see saw \\
sell sold & slay slew \\
speak spoke & steal stole \\
swear swore & take took \\
understand understood & think thought \\
weep wept & freeze froze \\
go went & break broke \\
catch caught & say said \\
seek sought & shake shook \\
stand stood & strike struck \\
tell told & weave wove \\
\hline
\end{tabular}

\begin{tabular}{|c|c|c|}
\hline \multicolumn{3}{|c|}{$\begin{array}{c}\text { APPENDIX C } \\
\text { Base Items and Primes of Associative Stimuli } \\
\text { from Experiment } 3\end{array}$} \\
\hline $\begin{array}{l}\text { ain ache } \\
\text { nife cut } \\
\text { irt earth } \\
\text { indow glass } \\
\text { ueen king } \\
\text { rder law } \\
\text { ink mind } \\
\text { nurch priest } \\
\text { ool sheep } \\
\text { nair table } \\
\text { anish disappear }\end{array}$ & $\begin{array}{l}\text { moth butterfly } \\
\text { nurse doctor } \\
\text { hand finger } \\
\text { nail hammer } \\
\text { cat kittens } \\
\text { tree leaf } \\
\text { hill mountain } \\
\text { stream river } \\
\text { web spider } \\
\text { carrot vegetable } \\
\text { buy purchase }\end{array}$ & $\begin{array}{l}\text { navy army } \\
\text { bird eagle } \\
\text { pepper salt } \\
\text { house home } \\
\text { light lamp } \\
\text { woman man } \\
\text { rat mouse } \\
\text { thief robber } \\
\text { sky star } \\
\text { city town }\end{array}$ \\
\hline
\end{tabular}

\begin{tabular}{|c|c|c|}
\hline \multicolumn{3}{|c|}{$\begin{array}{c}\text { APPENDIX D } \\
\text { Base Items and Primes of Synonymous Stimuli } \\
\text { from Experiment } 3 \\
\end{array}$} \\
\hline $\begin{array}{l}\text { istake error } \\
\text { arplus excess } \\
\text { adition custom } \\
\text { apper dinner } \\
\text { Im movie } \\
\text { ation country } \\
\text { oth fabric } \\
\text { ork labor } \\
\text { nergency crisis } \\
\text { hedule program }\end{array}$ & $\begin{array}{l}\text { victory triumph } \\
\text { trolley streetcar } \\
\text { homicide murder } \\
\text { worth value } \\
\text { currency money } \\
\text { pillar column } \\
\text { idea concept } \\
\text { tale story } \\
\text { drape curtain } \\
\text { minister pastor }\end{array}$ & $\begin{array}{l}\text { student pupil } \\
\text { bunny rabbit } \\
\text { sum total } \\
\text { vow promise } \\
\text { smell odor } \\
\text { gain profit } \\
\text { fowl poultry } \\
\text { energy vigor } \\
\text { part fraction } \\
\text { gorge canyon }\end{array}$ \\
\hline
\end{tabular}
autumn fall 